\title{
Hydrothermal processes facilitate rare metal fractionation and
}

\section{mineralization}

\author{
ZHEKUn ZHANG ${ }^{1}$, XING DING $^{2}$, MingXING LinG ${ }^{2}$, WEIDONG SUN ${ }^{3}$
}

${ }^{1}$ CAS Key Laboratory of Mineralogy and Metallogeny, Guangzhou Institute of Geochemistry, Chinese Academy of Sciences, Guangzhou 510640, China

${ }^{2}$ State Key Laboratory of Isotope Geochemistry, Guangzhou Institute of Geochemistry, Chinese Academy of Sciences, Guangzhou 510640, China

${ }^{3}$ Center of Deep Sea Research, Institute of Oceanology, Chinese Academy of Sciences, Qingdao 266071, China

The behavior of hydrothermal fluids at the magmatic-hydrothermal transition during the formation of intrusion-related ore deposits is poorly understood, and the role of hydrothermal process in facilitating concentrations and fractionations of rare-metal remains contentious. Here we present a coupled macro- and micro-observations on a 600-meter-long drilling hole from the Daping mineralized granite to decipher the behaviors of rare-metal and hydrothermal fluids. From the depth of $600 \mathrm{~m}$ to $\sim 350 \mathrm{~m}$, both $\mathrm{Nb}$ and $\mathrm{Ta}$ concentrations doubly increase whereas $\mathrm{Nb} / \mathrm{Ta}$ ratios overall decline. At the site about $350 \mathrm{~m}$ deep, $\mathrm{Nb}, \mathrm{Zr}$, REE, and Si show a cliff drop in concentrations whereas $\mathrm{Ta}$ and $\mathrm{Rb}$ display a reverse trend, which results in $\mathrm{Nb} / \mathrm{Ta}$ ratios decrease to less than 1. Till to the surface, their values display no significant fluctuation. Correspondingly, columbite-group minerals at $285 \mathrm{~m}$ have more complicated texture, represented by a wide Ta-rich overgrowth, than those at $540 \mathrm{~m}$, while the zircons at 285 $\mathrm{m}$ are mostly hydrothermal and richer in Hf than those at $540 \mathrm{~m}$. These results reveal that during the magmatic-hydrothermal transition hydrothermal fluids exsolved from the deep granitic melts are enriched in $\mathrm{F}, \mathrm{Na}, \mathrm{Rb}$, and rare metal elements, and can migrate upward to accumulate a hydrothermal "pond" in the granite cupola. Stable hydrothermal "pond" caused by fluid focusing should facilitate a prolonged interaction among hydrothermal fluids, granitic melts and early-formed crystals, producing a local re-equilibrium distribution of rare metal elements and strong albitization within the space of hundreds of meters.

This study was supported by National Key R\&D Program of China (2016YFC0600408). 